\section{Agreement in the diagnosis of dental fluorosis in central incisors performed by a standardized photographic method and clinical examination}

\author{
Concordância no diagnóstico da fluorose dentária \\ em incisivos centrais realizado por um método \\ fotográfico padronizado e pelo exame clínico
}

\author{
${ }^{1}$ Faculdade de Odontologia, \\ Universidade Federal de \\ Minas Gerais, Belo Horizonte, \\ Brasil. \\ 2 Departamento de \\ Bioquímica, Centro de \\ Pesquisas Odontológicas \\ São Leopoldo Mandic, \\ Campinas, Brasil. \\ Correspondence \\ C. C. Martins \\ Departamento de \\ Odontopediatria e \\ Ortodontia, Faculdade de \\ Odontologia, Universidade \\ Federal de Minas Gerais. \\ Rua Carangola 62, apto. 101, \\ Belo Horizonte, $M G$ \\ 30330-240, Brasil. \\ carolcm10@hotmail.com
}

\begin{abstract}
The aim of this study was to assess agreement in the diagnosis of dental fluorosis performed by a standardized digital photographic method and a clinical examination (gold standard). 49 children (aged 7-9 years) were clinically evaluated by a trained examiner for the assessment of dental fluorosis. Central incisors were evaluated for the presence or absence of dental fluorosis and were photographed with a digital camera. Photographs were presented to three pediatric dentists, who examined the images. Data were analyzed using Cohen's kappa and validity values. Agreement in the diagnosis performed by the photographic method and clinical examination was good (0.67) and accuracy was $83.7 \%$. The prevalence of dental fluorosis was reported to be higher in the clinical examination (49\%) compared with the photographic method (36.7\%). The photographic method presented higher specificity (96\%) than sensitivity (70.8\%), a positive predictive value (PPV) of $94.4 \%$ and a negative predictive value (NPV) of 77.4\%. The diagnosis of dental fluorosis performed using the photographic method presented high specificity and PPV, which indicates that the method is reproducible and reliable for recording dental fluorosis.
\end{abstract}

Dental Photography; Dental Fluorosis; Reproducibility of Results; Sensitivity and Specificity

\author{
Carolina Castro Martins 1 \\ Loliza Chalub 1 \\ Ynara Bosco Lima-Arsati 2 \\ Isabela Almeida Pordeus 1 \\ Saul Martins Paiva 1
}

\section{Introduction}

One major factor that hampers comparisons between epidemiologic studies of enamel defects is the great variety of methodologies used. Dental fluorosis has several fluorosis-specific criteria used for its diagnosis 1,2,3,4. Studies of the diagnosis of dental fluorosis can be affected by a large number of factors, such as examiner bias, intraexaminer and inter-examiner reliability, examiner drift, index validity and varying methodologies (teeth dried or not; duration of drying; cleaning of teeth and lighting used) 5 .

Photographs are employed in multi-center epidemiological surveys to provide a permanent record of teeth $5,6,7,8$. In epidemiological studies of dental fluorosis, the photographic method offers the following advantages: images can be read by trained examiners, blinded to the fluoridation status of the subject; images can be doublescored and cross-checked with the development of consensus of divergent scores; and images are a permanent record of the enamel, useful for measuring changes in enamel over time 6,9,10.

Problems often encountered in images of anterior teeth include specular reflection and lip shadow. Such problems occur due to the position of the flash and the angle of the light. Therefore, an experienced and trained examiner is necessary when taking standardized photos in order to minimize both specular reflection and lip shadow ${ }^{5}$. Another disadvantage of the method is that 
photographs can increase the cost of the study, which would probably not occur if the clinical examination alone were conducted.

The photographic method has aroused the interest of epidemiologists. Despite the great advances in digitalized images, conventional photographs are more often used in epidemiologic research. The digital camera offers the following advantages: It maintains confidentiality, as it can photograph the teeth alone; measurements of variation in density are possible with digital images 5; greater resolution increases the definition of the image; and images can be easily stored in digital systems. Disadvantages of the digital camera include the need for an experienced, trained photographer and the increased cost of the equipment.

A number of studies have compared the prevalence of enamel opacities in children using conventional photographs and clinical examination $9,11,12$, but information is scarce on the quality of the photographic method and its reproducibility compared with clinical diagnoses 13,14. The aim of the present study was to compare the agreement between the diagnosis of dental fluorosis using a standardized digital photographic method and a clinical examination (gold standard).

\section{Methods}

The present study was conducted using a convenience sample of 49 children, aged between 7 and 9 years, who had been involved in a prospective Brazilian dental fluorosis study 15,16. Children were life-long residents of two Brazilian cities, Ibiá (Minas Gerais State) and Piracicaba (São Paulo State). Both cities have optimally adjusted fluoridated water [0.7 parts per million of fluoride (ppm F); range 0.6-0.8ppm F]. The eligibility criteria included children without dental fluorosis and children with a very mild degree of dental fluorosis, since the very mild degree is the most prevalent degree of dental fluorosis in children living in areas with optimally fluoridated water supply 6,12,17,18.

Approval to conduct the research was received from the Human Research Ethics Committee of the Federal University of Minas Gerais. Parents signed informed consent terms for their children to take part in the study.

\section{Clinical examination (gold standard)}

All children were clinically evaluated by a single calibrated examiner (C.C.M.). Prior to the examination, children were asked to brush their teeth with a toothbrush and fluoridated toothpaste in order to remove plaque. All examinations were conducted in the child's home during daylight hours. Children were positioned standing upright in front of the examiner, who remained seated on a chair. A portable lantern on the examiner's head (Tikka XP, Peltz, Crolles, France) provided the artificial light for examining the teeth. To conduct the clinical examination, a dental mirror (Prisma, São Paulo, Brazil) and gauze to dry teeth were also used 5,6. Maxillary and mandibular central permanent incisors were evaluated as to the presence or absence of dental fluorosis. Presence was considered when at least two teeth presented dental fluorosis.

\section{Photographic method}

After the clinical examination, photographs were taken of the maxillary and mandibular central permanent incisors of the children in closed edge-to-edge contact. A Mavica CD500 (Sony Eletronics Inc., San Diego, USA) digital camera was used, with a resolution of 2048 x 1536, flash on, $52 \mathrm{~mm}$ Carl Zeiss lens, fine quality level, macro function, InfoLithium battery (NP-FM50) and charger. Images were recorded on a CD, Mavica CD-ROM (Sony Eletronics Inc., San Diego, USA), 156 megabytes.

Each child was positioned leaning against a wall contrary to the daylight, with the Frankfortmaxillary plane parallel to the floor. A cheek retractor was inserted into the child's mouth and the child was asked to close the incisors in edgeto-edge contact. Teeth were allowed to dry naturally and photos were taken after 1 minute and 30 seconds 5,6. The camera was positioned according to the specifications of Cochran et al. 5 , at the

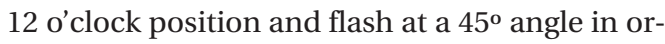
der to reduce specular reflection and lip shadow.

The recorded images were printed in a commercial photographic laboratory in Belo Horizonte, Brazil, on the same day in order to minimize variations. Images were printed on Kodak Royal Digital opaque paper, size $15 \times 21 \mathrm{~cm}$. Problems in images, such as non-centered teeth, the presence of lip shadow, specular reflection and tremulous images were minutely evaluated. When these problems were eliminated from the images, the photographs were deemed suitable for conducting the main study.

Three pediatric dentists who were not part of the study staff were asked to evaluate the photos. Photos were mixed randomly and were presented separately to each pediatric dentist during daylight hours. Dentists were blind to the child's residence, clinical examination and their colleagues' evaluations. They were asked to evaluate the central incisors, classifying them with regard to the 
presence or absence of dental fluorosis. The final photographic diagnosis of dental fluorosis was based on the classification agreement between at least two of the three dentists. For example, if two dentists considered fluorosis present and one considered fluorosis absent, the photographic diagnosis was the presence of dental fluorosis.

\section{Calibration exercise}

A calibration exercise was conducted prior to the study. For the clinical examination (gold standard), the calibration program was carried out by a single dentist (C.C.M.). 24 children aged 7 to 9 years (not part of the study population) were randomly selected from schools in Ibiá and included in the calibration process. Twelve children were examined and re-examined after a one-week interval for the calculation of intra-examiner agreement, using Cohen's kappa at the person level, obtaining a value of 0.42 . As the kappa value was not good, the calibration exercise was conducted again with another twelve children. This time the kappa value was 0.95 , at which point the researcher was considered capable of conducting the main study.

For diagnosis of dental fluorosis through photographs, a calibration exercise was also conducted separately with each one of the three pediatric dentists. Training for photographic diagnosis entailed the use of color photographs (different photographs from those of the main study) to show the major clinical characteristics of each situation of interest and the situations to be considered in the differential diagnosis. Dental fluorosis images were shown to the dentists one and two weeks later. Kappa values for intraexaminer agreement among the three pediatric dentists ranged from 0.79 to 0.85 and inter-examiner agreement ranged from 0.50 to 0.69 .

\section{Statistical analysis}

Data were entered on the Excel (Microsoft Corp., USA) program and analyzed using the STATA/SE 8.0 (Stata Corp., College Station, USA) and Minitab (Minitab Inc., State College, USA) programs, which compared the photographic method with the gold standard (clinical examination). Cohen's kappa statistic was used to measure the reproducibility of the photographic method and the reproducibility of each of the dentists 19 compared to the gold standard. Kappa interpretation was the following: $\leq 0.20$ (poor); $0.21-0.40$ (fair); 0.41-0.60 (moderate); 0.60-0.80 (good) and 0.801.00 (very good) 20. Accuracy, sensitivity, specificity, positive predictive value (PPV), negative predictive value (NPV) and likelihood ratio (LR) of the test were calculated. The Receiver Operating Characteristic (ROC) was calculated to determine the variation of sensitivity and specificity of a test, with higher sensitivity indicating a greater validity 21 .

\section{Results}

A total of 49 children aged 7 to 9 took part in the present study [20 girls $(40.8 \%)$ and 29 boys (59.2\%)]. 32 children lived in Ibiá and 17 in Piracicaba. 24 (49\%) of the 49 children examined clinically presented dental fluorosis in at least two of the four central permanent incisors.

Table 1 displays the agreement between the diagnosis from clinical examination (gold standard) and the diagnosis carried out using the photographic method for each one of the three dentists, as measured by Cohen's kappa. Agreement between each dentist and the gold standard ranged from "moderate" to "good" (0.460.67). Agreement between the gold standard and the photographic method, which is the diagnosis that agreed with at least two of the three dentists, was considered "good" (0.67).

The prevalence of dental fluorosis was $49 \%$ through the clinical examination (24 cases of dental fluorosis) and $36.7 \%$ through the photographic method (18 cases) (Table 2). Accuracy was $83.7 \%$. The diagnosis through the photographic method had higher specificity (96\%) than sensitivity (70.8\%), PPV of $94.4 \%$ and NPV of 77.4, LR+ of 17.7 and LR- of 0.3. Figure 1 shows an area of $83.4 \%$ under the ROC curve for photographic method.

\section{Discussion}

The development of a photographic method for evaluating dental fluorosis is currently widely discussed for epidemiological research and offers

Table 1

Level of agreement in the diagnosis of dental fluorosis performed by clinical examination (gold standard) and photographic examination.

\begin{tabular}{lc}
\hline & Kappa value \\
\hline Dentist A & 0.67 \\
Dentist B & 0.46 \\
Dentist C & 0.67 \\
Final diagnosis by the photographic method * & 0.67 \\
\hline
\end{tabular}

* Final diagnosis was based on the agreement of at least two of the three dentists. 
Frequency of dental fluorosis comparing the diagnosis performed by clinical examination (gold standard) and photographic method.

\begin{tabular}{lllcr}
\hline Test & & \multicolumn{2}{c}{ Clinical examination (gold standard) } \\
& & \multicolumn{2}{c}{$\begin{array}{c}\text { Dental fluorosis } \\
\text { Absent N (\%) }\end{array}$} \\
& Positive & $17(70.8)$ & $1(4.0)$ & $18(36.7)$ \\
Photographic method & Negative & $7(29.2)$ & $24(96.0)$ & $31(63.3)$ \\
& Total & $24(100.0)$ & $25(100.0)$ & $49(100.0)$ \\
\hline
\end{tabular}

Accuracy: 0.8367 (83.7\%); Sensitivity: 0.7083 (70.8\%); Specificity: 0.96 (96\%); Positive predictive value (PPV): 0.9444 (94.4\%); False positive value (FPV): 0.0556 (5.6\%); Negative predictive value (NPV): 0.7742 (77.4\%); False negative value (FNV): 0.2257 (22.6\%); Likelihood ratio of a positive test $(\mathrm{LR}+)$ : 17.7; Likelihood ratio of a negative test (LR-) $=0.3$.

Figure 1

ROC curve for photographic method.

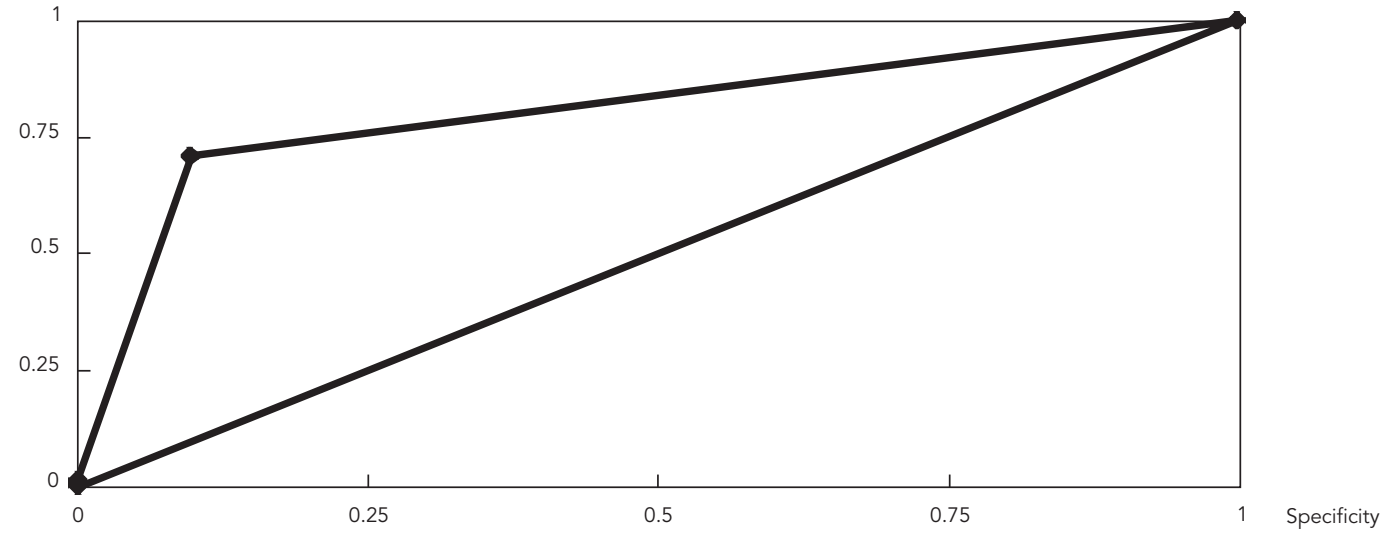

the following advantages: a permanent record of the enamel condition that can be compared at other points in time; the assessment of changes in the enamel over time; and the possibility of conducting evaluations that are blind to the conditions of the subject 5 . Most studies have conducted trials using conventional photographs. The present study used digital imaging for the photographic method. The digital camera offers the following advantages that justify its use: it maintains confidentiality, as it can photograph the teeth alone; measurements of variation in density are possible with digital images 5 ; greater resolution increases the definition of the image; the digital camera presents a better cost-benefit. With conventional photography, one can only see the image quality after the photograph has been developed and some will be unusable or lost. In a multi-centered European study, approximately $2.2 \%$ of the conventional photographs were not suitable for analysis 6 . With the aid of the digital camera, the photographer is able to evaluate image quality instantly and in cases of poor quality, the method can be immediately repeated. This decreases the risk of lost data and consequently eliminates the cost of developing a photograph that is not suitable for analysis, thereby increasing the cost-benefit.

When comparing the diagnosis performed by clinical and photographic assessments, there is a possibility of bias due to foreknowledge of the clinical situation. Thus, the photographs were 
randomly ordered and shown to three dentists who were blind to the clinical condition and place of residence of the subject. Agreement between the diagnosis found by each dentist and the clinical examination (Table 1) varied from "moderate" to "good", which is noteworthy, as dental fluorosis cases were "very mild". The "very mild" degree represented narrow lines corresponding to the perikymata 2 .

Agreement between the diagnosis of each dentist (0.46-0.67) and the gold standard was very close to the agreement between the final diagnosis of the photographic method and the gold standard (0.67). The "good" agreement between the diagnosis of the photographic method and the clinical examination is in accordance with another study that presented a kappa value of 0.63 between photographs and clinical examination ${ }^{13}$. Wong et al. ${ }^{14}$ compared the photographic method and clinical examination in different positions: one-view (frontal-view), three-view (frontal view and left and right lateral views) and five-view images (frontal-view, left and right lateral views, and upper and lower views). The authors found an agreement of 0.79 between the one-view photograph and clinical assessment, which is a higher value than that of the present study. Kappa values for the three-view and five-view images were 0.85 . The authors suggest that the one-view image failed in detecting the prevalence of enamel defects in canines, whereas proved adequate in assessing the prevalence of enamel defects in incisors. Based on these results, the one-view photograph used in the present study was adequate, as only central incisors were evaluated.

The prevalence of dental fluorosis was higher when the diagnosis was performed by the clinical examination than when performed by the photographic method (49\% and $36.7 \%$, respectively). Different techniques for the assessment of dental fluorosis were used: for the clinical examination, teeth were dried with gauze; for the photographic method, teeth were let to dry naturally. Although we standardized this aspect of the method according to previous studies 5,6, we believe that the difference in techniques used may have contributed to the higher prevalence of dental fluorosis determined by the clinical examination. However, a study conducted in two communities in England also found a higher prevalence of dental fluorosis through clinical examination (38\%) than the photographic method (37\%) 12. Another study conducted with other children from Piracicaba reported a $36.9 \%$ prevalence of dental fluorosis through the photographic method, which is very close to that of the present study 22 . Both studies reported a prevalence of dental fluoro- sis very close to that found in the present study when the photographic method is considered. Contrarily, other studies have found a higher prevalence using photographs when compared to clinical assessment 9,11 .

The photographic method may have inherent problems such as lip shadow, specular reflection, non-centered teeth and tremulous images 5,6. As a digital camera was used in the present study, these problems were immediately evaluated after the photograph was taken, which is a recourse that is not available in conventional cameras. If the problems were identified, the photograph was taken again. The presence of these problems in the photographs used for dental fluorosis diagnosis can influence the results. Differences in the prevalence of dental fluorosis between the diagnosis made by clinical examination and the photographic method could be explained by these kinds of problems in the photographs. For example, some specular reflection, although minimal, could have confused the examiners during the photographic diagnosis. Specular reflection predominantly affects the upper central incisors, making the image brighter. Thus, some dental fluorosis could have gone unnoticed by the dentists. The attempt to minimize the specular reflection can cause the lip shadow, which affects the lower central incisors more. Lip shadow is the shadow of the lower lip over the lower central incisors that can make the image darker. Tremulous images can cause gosh images and non-centered teeth can draw the focus to the teeth other than central incisors. All these problems can influence the diagnosis and confuse the dentists during the photographic diagnosis. Moreover, any differences between the group of three examiners and the gold standard could be either due to differences between the examiners or clinical versus photographic appearances.

Despite the higher prevalence of dental fluorosis when the diagnosis was performed through the clinical examination in comparison to the photographic method, accuracywashigh (83.7\%). The accuracy of the test is the proportion of all tests having given a correct result 23 , which were 43 cases in the present study. The photographic method presented higher specificity than sensitivity $(96.0 \times 70.8 \%$, respectively). Specificity is the probability that the test will correctly exclude people without the disease, whereas, sensitivity is the probability of the test to screen positive people who have the disease 23 . The results indicate that the photographic method is better for diagnosing the absence of dental fluorosis rather than its presence. As displayed in Table 2, among the 25 children without dental fluorosis in the central incisors, 24 were correctly diagnosed as 
negative through the photographic method. On the other hand, the proportion of correct diagnosis for the presence of dental fluorosis was 17 from 24 cases.

The photographic method also presented a higher PPV (94.4\%) than NPV (77.4\%). The PPV is the probability of those persons screening positive of actually having the disease 23 . In other words, it is the probability that the child presents dental fluorosis if the photographic diagnose is positive. Based on the present data, when the photographic method establishes a positive diagnose of fluorosis on an enamel surface, there is a $94.4 \%$ of it being correct. The remaining $5.6 \%$ are the false positives. As displayed in Table 2, among the 18 positive cases diagnosed through the photographic method, 17 were correct and one case was a false positive.

The same can be said about the NPV. NPV is the probability of people screening negative of not actually having the disease 23 , which was $77.4 \%$ in the present study. In other words, when the photographic method determines a negative diagnosis for dental fluorosis, there is a $77.4 \%$ chance of it being correct. The other $22.6 \%$ correspond to false negatives. As displayed in Table 2, among the 31 negative cases diagnosed through the photographic method, 24 were correct (did not present fluorosis), but there was a high number of incorrect diagnoses (7 false negatives).

The likelihood ratio for a positive test $(\mathrm{RT}+)$ was 17.70 and the likelihood ratio for a negative test (LR-) was 0.30 . The LR+ is how much more likely a positive test is to be found in a person with the condition than in a person without it, and the LR- is how much more likely a negative test is to be found in a person without the condition than in a person with it 23 . The test is better the more LR differs from 1, that is, greater than 1 for LR+ and less than 1 for LR- 24. The results indicate a greater value than 1 for LR+ (17.7) and lower than 1 for LR- (0.3).

The area under the ROC curve represents the relationship between sensitivity and specificity, for which outcome values closer to $100 \%$ indicate a better test (24). A straight line divides the graph in two: $50 \%$ above and below the ROC curve. If the area under the curve is below $50 \%$, this means that the test is useless 24 . The present study revealed an area under the ROC curve of $83.4 \%$, which is a high value, indicating that the photographic method is good for the assessment of dental fluorosis.

The study has some limitations that should be addressed, namely, the small sample size and the small number of dentists who evaluated the photographs can influence kappa and validity values. The present study employed only the front view of central incisors. Although it is possible to record lateral, upper and lower views, in larger epidemiological surveys, multiple views increase the cost of the study. Thus, it is more common to employ one view of anterior teeth for further evaluation. In the present study, the teeth evaluated had very mild degrees of dental fluorosis. Further studies on diagnosis agreement involving higher degrees of dental fluorosis are needed and should be encouraged.

The digital photographic method is relatively new among epidemiological studies. The development of new digital systems and the increase in the number of digital cameras on the market offer a new possibility for epidemiologic studies. Further studies comparing digital photography with conventional photography are very welcome. Besides the reproducibility of the method, the digital photograph offers a good cost-benefit for epidemiological research. Both conventional and digital photographic methods are attracting the interest of epidemiologists and should be the subject for future research.

The diagnosis of dental fluorosis performed using the photographic method proved reproducible and reliable when compared to the diagnosis performed by clinical examination. The use of the photographic method presented high specificity and PPV, which indicates that it is satisfactory for recording dental fluorosis with very few cases of false positives. The method proved adequate in recording enamel surfaces and in the assessment of dental fluorosis. 


\section{Resumo}

O objetivo do estudo foi comparar o diagnóstico de fluorose dentária realizado por um método fotográfico com o exame clínico (padrão ouro). Quarenta e nove crianças, de 7 e 9 anos, foram clinicamente examinadas por um examinador calibrado para fluorose dentária. Os incisivos foram fotografados com câmera digital e as fotografias foram apresentadas a três odontopediatras, que examinaram as imagens. A concordância por kappa entre o método fotográfico e o padrão ouro foi boa $(0,67)$ e a acurácia foi de $83,67 \%$. A prevalência de fluorose dentária foi levemente maior pelo método clínico (49\%) do que pelo fotográfico (36,7\%). O método fotográfico apresentou maior especificidade (96\%) que sensibilidade (70,83\%), valor de predição positivo (VPP) de 94,44\% e valor de predição negativo (VPN) de 77,42\%, com poucos casos de falsos positivos (6\%). O diagnóstico de fluorose dentária usando-se o método fotográfico apresentou alta especificidade e VPP, indicando que é adequado para registrar fluorose dentária, com poucos casos de falsos positivos. O método é reprodutível e confiável quando comparado com o diagnóstico clínico e pode ser usado para o diagnóstico da fluorose dentária.

Fotografia Dentária; Fluorose Dentária; Reprodutibilidade dos Testes; Sensibilidade e Especificidade

\section{References}

1. Dean HT, Arnold FA. Endemic dental fluorosis or mottled enamel. J Am Dent Assoc 1943; 30: 1278-83.

2. Thylstrup A, Fejerskov O. Clinical appearance of dental fluorosis in permanent teeth in relation to histologic changes. Community Dent Oral Epidemiol 1978; 6:315-28.

3. Horowitz HS, Driscoll WS, Meyers RJ. A new method for assessing the prevalence of dental fluorosis: the Tooth Surface Index of Fluorosis. J Am Dent Assoc 1984; 109:37-41.

4. Pendrys DG. The Fluorosis Risk Index: a method for investigating risk factors. J Public Health Dent 1990; 50:291-8.

5. Cochran JA, Ketley CE, Sanches L, Mamai-Homata E, Oila A-M, Árnadóttir IB, et al. A standardised photographic method for evaluating enamel opacities including fluorosis. Community Dent Oral Epidemiol 2004; 32:19-27.

\section{Contributors}

C. C. Martins, I. A. Pordeus and S. M. Paiva conceptualized the rationale and design of the study. C. C. Martins, L. Chalub and Y. B. Lima-Arsati carried out the data collection, statistical analysis and data interpretation. C. C. Martins and S. M. Paiva drafted the manuscript. All authors read and approved the final manuscript.

\section{Acknowledgments}

This study was supported by the Coordenating Agency for Graduate Studies (CAPES) and Brazilian Council for Scientific and Technological Development (CNPq).
6. Cochran JA, Ketley CE, Árnadóttir IB, Fernandes B, Koletsi-Kounari H, Oila A-M, et al. A comparison of the prevalence of fluorosis in 8-year-old children from seven European study sites using a standardised methodology. Community Dent Oral Epidemiol 2004; 32:28-33.

7. O'Mullane DM, Cochran JA, Whelton HP. Fluoride ingestion from toothpaste: background to European Union-funded multicentre project. Community Dent Oral Epidemiol 2004; 32:5-8.

8. O'Mullane DM, Ketley CE, Cochran JA, Whelton HP, Holbrook WP, van Loveren C, et al. Fluoride ingestion from toothpaste: conclusions of European Union-funded multicentre project. Community Dent Oral Epidemiol 2004; 32:74-6.

9. Levine RS, Beal JF, Fleming CM. A photographically recorded assessment of enamel hypoplasia in fluoridated and non-fluoridated areas in England. Br Dent J 1989; 166:249-52. 
10. Whelton HP, Ketley CE, McSweeney F, O'Mullane DM. A review of fluorosis in the European Union: prevalence, risk factors and aesthetic issues. Community Dent Oral Epidemiol 2004; 32:9-18.

11. Rock WP, Sabieha AM. The relationship between reported toothpaste usage in infancy and fluorosis of permanent incisors. Br Dent J 1997; 183:165-70.

12. Tabari ED, Ellwood R, Rugg-Gunn AJ, Evans DJ, Davies RM. Dental fluorosis in permanent incisor teeth in relation to water fluoridation, social deprivation and toothpaste use in infancy. Br Dent J 2000; 189:216-20.

13. Ellwood RP, Côrtes DF, O'Mullane DM. A photographic study of developmental defects of enamel in Brazilian school children. Int Dent J 1996; 46: 69-75.

14. Wong HM, McGrath C, Lo ECM, King NM. Photographs as a means of assessing developmental defects of enamel. Community Dent Oral Epidemiol 2005; 33:438-46.

15. Paiva SM, Lima YBO, Cury JA. Fluoride intake by Brazilian children from two communities with fluoridated water. Community Dent Oral Epidemiol 2003; 31:184-91.

16. Martins CC, Paiva SM, Lima-Arsati YB, RamosJorge ML, Cury JA. Prospective study of the association between fluoride intake and dental fluorosis in permanent teeth. Caries Res 2008; 42:125-33.
17. Gonini CAJ, Morita MC. Dental fluorosis in children attending basic health units. J Appl Oral Sci 2004; 12:189-94.

18. Wondwossen F, Astrom AN, Bjorvatn K, Bardsen A. The relationship between dental caries and dental fluorosis in areas with moderate and high fluoride drinking water in Ethiopia. Community Dent Oral Epidemiol 2004; 32:337-44.

19. Cohen J. A coefficient of agreement for nominal scales. Educ Psychol Meas 1960; 20:37-46.

20. Altman DG. Practical statistics for medical research. London: Chapman \& Hall; 1991.

21. Swets JA. The relative operating characteristics in psychology: a technique for isolating effects of response bias finds wide use in the study of perception and cognition. Science 1973; 182:990-1000.

22. Menezes LMB, Sousa MLR, Rodrigues LKA, Cury JA. Self-perception of fluorosis due to fluoride exposure to drinking water and dentifrice. Rev Saúde Pública 2002; 36:752-4.

23. Greenhalgh T. How to read a paper: papers that report diagnostic or screening tests. BMJ 1997; 315:540-3.

24. Knottnerus JA, van Well C, Muris JWM. Evaluation of diagnostic procedures. BMJ 2002; 324:477-80.

Submitted on 28/Apr/2008

Final version resubmitted on $25 / \mathrm{Jul} / 2008$

Approved on 05/Aug/2008 